\title{
Corpo, metamorfoses, cuidados: uma formação possível com profissionais de saúde
}

\author{
Thiago de Sousa Freitas Lima, I Tulio Alberto Martins de Figueiredo, ${ }^{I I}$ Marcia Oliveira Moraes ${ }^{I, \star}$ \\ ${ }^{I}$ Universidade Federal Fluminense, Niterói, RJ, Brasil

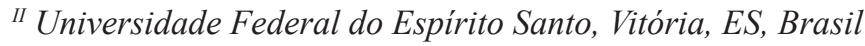

\begin{abstract}
Resumo
Este artigo apresenta proposta de intervenção no campo da formação em saúde denominada "clínica da metamorfose”. O campo para o estudo foi um grupo de pesquisa em saúde, vinculado a um Programa de Pós-Graduação em Saúde Coletiva, de uma universidade pública. Os participantes eram profissionais, estudantes e pesquisadores de diversas áreas da saúde. Foram utilizadas experimentações com movimentos de consciência corporal, diário de campo e relatos escritos pelos participantes após a vivência. O cultivo do material se deu a partir de uma política narrativa que articulou o diário de campo dos movimentos vivenciados com as falas e relatos dos participantes. A intervenção propiciou um espaço de reflexão que levou os participantes a relataram maior capacidade de atenção às suas relações cotidianas e de trabalho, aumento de sensibilidades e transformação de comportamentos padronizados em novas formas de se articular.
\end{abstract}

Palavras-chave: formação em saúde; corpo; cuidado.

\section{Body, metamorphoses and care: a possible formation with health professionals}

\begin{abstract}
This article presents an intervention proposal titled "metamorphosis clinic", fulfilled in the realm of health education. The field for the study was a health research group, linked to a Post-Graduate Program in Collective Health, of a public university. Participants were professionals, students and researchers from various health areas. Experimentations were used with movements of body awareness, field diary and reports written by the participants after the experience. The cultivation of the material was based on a narrative policy that articulated the field diary of the movements experienced with the speeches and reports of the participants. The intervention provided a space for reflection that led the participants to report greater capacity for attention to their daily and work relationships, increase of sensitivities and transformation of standardized behaviors into new ways of living.
\end{abstract}

Keywords: health formation; body; care.

\section{Introdução}

O presente artigo visa atravessar algumas questões que colocam em relação corpo, cuidado e a problemática da formação em saúde. Para tanto, como fio condutor, será relatada uma intervenção ${ }^{1}$ realizada em um grupo de pesquisa de um Programa de Pós-Graduação em Saúde Coletiva, frequentado por profissionais e estudantes da área da saúde. Trata-se de abordar o tema da formação em saúde a partir de sua dimensão sensível. Tentamos, assim, tencionar a emergência de estudos e dispositivos que apontem para promoção e problematização das tecnologias relacionais como parte constitutiva das políticas e formações de profissionais em saúde.

Sabe-se que a educação em saúde é um campo multifacetado, para o qual convergem diversas concepções, das áreas tanto da educação, quanto da saúde. O conceito de saúde, por sua vez, lida com problemas complexos, que se referem ao modo de viver, sofrer, adoecer e morrer da população, superando os limites do enfoque orgânico/ biológico (ALMEIDA FILHO, 2000). Em nossa perspectiva, o conceito de saúde alcança dimensões mais amplas com interseções de fatores sociopolíticos, econômicos,

\footnotetext{
^Endereço para correspondência: Universidade Federal Fluminense, Departamento de Psicologia. Campus do Gragoatá, s/n ${ }^{\circ}$ Bloco O, sala 310 - São Domingos. Niterói, RJ - Brasil. CEP: 24210-350.E-mail: lima.thiagosousa@hotmail. com, tulioamf.ufes@gmail.com,mmoraes@vm.uff.br

${ }^{1}$ Tal intervenção é parte integrante do trabalho de pesquisa: "Por uma clínica dos poros: conhecimento e práticas em saúde a partir do exercício de um corpo sensível" (LIMA, 2014).
}

industriais e históricos. Logo, o modelo pedagógico deve ampliar o conceito de saúde com inovações politico-pedagógicas, fugindo da concepção informativa e representacional. (CARVALHO; CECCIM, 2009).

A formação em saúde se encontra, não raras vezes, impregnada de pressupostos representacionais que se espelham no pensamento moderno ${ }^{2}$ de uma reprodução da realidade que se dá a priori. Trata-se, nesse caso, de supor que a formação ocorre, exclusivamente, através da transmissão de informações que representam, em última instância, uma realidade dada de antemão. A relação ensino-aprendizagem segue uma lógica unilateral na qual a avaliação baseia-se na capacidade de absorção e de reprodução do conteúdo (CARVALHO; CECCIM, 2009). Tais concepções cognitivas influenciam diretamente nas práticas em saúde. Acumulam uma tradição caracterizada por um formato centrado em conteúdos herméticos e numa pedagogia de transmissão de informações desconexas entre as disciplinas. Conforme discutem Carvalho e Ceccim (2009, p. 143):

Os fatores de exposição às aprendizagens estão centrados no professor, no livro de texto e nos estágios supervisionados e não na produção de experiência de si e de apropriação dos entornos da vida; os currículos são organizados em

${ }^{2}$ Definimos pensamento moderno no sentido proposto por Bruno Latour (1994): como um conjunto de práticas que separam natureza de um lado, sociedade de outro. 
unidades disciplinares conteudistas e não em unidades de produção pedagógicas [...].

Por meio destas discussões, revela-se a importância da investigação de dispositivos que possam promover um processo formativo compromissado com a garantia das condições sociais necessárias à saúde da comunidade (CARVALHO; CECCIM, 2009).

Nesse sentido, Paim (2008), nos alerta para a necessidade de problematização do objeto das práticas de saúde coletiva e a reflexão sobre o conceito de saúde, impondo redefinições na formação básica dos profissionais em saúde. Seguindo sua análise, o autor menciona a urgência na criação de novas estratégias que superem o "modo escolar" e a hegemonia individualista de encarar a saúde. Novas abordagens formativas que instrumentalizem o sujeito para o atendimento das coletividades. Nesse caminho, tal escrita busca conhecer novas apostas que podem ser aliadas na formação de um profissional em saúde coletiva.

Nesse contexto, segundo Ayres (2004), presenciamos o surgimento de uma série de novos discursos no campo da saúde coletiva, tais como a promoção da saúde, vigilância da saúde, saúde da família, redução de vulnerabilidade, entre outros. Contudo, uma efetiva consolidação dessas propostas tenciona por transformações bastante radicais no nosso modo de saber e agir em saúde, especialmente no que diz respeito às suas caixas de ferramentas conceituais (MERHY, 2002).

Fazer a discussão da formação em saúde longe de uma perspectiva conteudista ou representacional, nos leva a repensar também as práticas de cuidado em saúde. Nesse ponto, esse artigo segue as pistas abertas por Manso (2015) quando afirma que o cuidado é prática coletiva, distribuída e localizada. A autora propõe que o campo da saúde coletiva, instruído pelos pilares do SUS, abre a possibilidade de se redesenhar os sentidos do cuidado na direção de uma prática que envolve articular humanos e não humanos, de forma situada e distribuída. Citando Mol, Manso menciona que na prática do cuidado

[...] não se pretende definir de antemão como será o cuidado e os seus efeitos. Esse é entendido como um processo e, por isso, não tem fronteiras claras, é aberto [...] O cuidado é uma questão de tempo. Ele não é um produto que passa de mão em mão, mas sim é uma questão onde várias mãos trabalham juntas, ao longo do tempo em busca de um resultado [...] Cuidado é [...] uma interação que retorna e retorna em um processo continuo [...] O processo de cuidado envolve um time, profissional, maquina, medicação, corpos, pacientes e muitas outras coisas relevantes e as tarefas são divididas entre os membros desse time sempre em constante mutação (MOL apud MANSO, 2015, p. 161).

Por definir-se como prática coletiva, relacional, o cuidado se qualifica por um conhecimento que não cria produtos, não gera procedimentos metódicos, não cria generalizações, posto que só cabe como prática local, tecida no e com o território. Mais do que tratar de um objeto, a intervenção em saúde se articula com cuidar quando o sentido da intervenção passa a ser não apenas o alcance de um estado de saúde idealizado, mas antes uma certa reorganização possível do que conta ou não conta como saúde possível naquele cenário (MANSO, 2015).

$\mathrm{O}$ direcionamento do cuidar opera no campo da micropolítica, no exame da relação entre as nuances afetivas do encontro. Em seu sentido prático, trata-se de suportar um diálogo mais interessado possível com problemas complexos, que se referem ao modo de viver, sofrer, adoecer e morrer da população.

A dimensão do cuidado caminha com desestruturas - implica em mutações corporais tanto dos profissionais quanto dos usuários para compor vínculo e direção emancipatória (PIRES, 2005). Instaura-se no jogo de corpos a principal ferramenta disponível para efetivar este vínculo.

Considerar outros elementos que participem da formação de um corpo permite pensá-lo como plano onde se agenciam forças que o hierarquizam, segmentam e tendemos a naturalizá-las.

É nessa perspectiva que o construto "cuidado de si” é definido, referindo-se às ocupações e técnicas corporais que ativam a construção, a manutenção e a transformação de si. O cuidado opera como uma categoria que mais expressivamente consegue nos colocar em sintonia com esse plano de fluxos e forças, sem começo nem fim, no qual o ser do humano resulta de sua ocupação de si como resultado de si (AYRES, 2004).

Neste artigo, apresentamos alguns efeitos de uma intervenção realizada com profissionais de saúde, seguindo inspirações cartográficas. De acordo com Passos, Kastrup e Escóssia (2010) e Rolnik (2006), a cartografia como método, não pressupõe uma orientação do trabalho do pesquisador de modo prescritivo. Há uma inseparabilidade entre conhecer e fazer, intervir e pesquisar. Considera-se que sujeito, objeto e conhecimento são efeitos coemergentes do processo de pesquisar. Tal processo de coemergência se dá pelos agenciamentos instalados na experiência enquanto campo intensivo da produção de realidades. O método que embasou a intervenção que ora apresentamos afirma este conceito em sua radicalidade ao ativar corpos em movimento, alimentando desassossegos e perturbações. Movimentos que trabalham na quebra de formas instituídas para dar expressão aos processos de institucionalização e geradores de um conhecimento sensível.

Para além de interpretações, esta manobra metodológica permite pôr em discussão a relação do corpo com suas mobilizações. Treinar modos de expressão coletivos de um corpo atravessado por questões institucionais e científicas e que ganha mais corpo ao descrever o que lhes é proposto: como é ser afetado por uma experiência. Buscamos por dispositivos que não fracionassem corpo - consciência; interior - exterior, mas que se voltassem para a experiência e seus rastros de cuidado.

Optou-se por trabalhar com o conceito de intervenção como um difuso de teorias, pragmáticas, estratégias, táticas e técnicas que se baseiam na participação ativa e inventiva dos sujeitos por meio de técnicas artísticas, pedagógicas e psicoterápicas. A finalidade de tais proce- 
dimentos consiste em fazê-las proliferar e conceber outras formas de existir, sempre singulares e performativas (BAREMBLITT, 2010).

Assim, entendemos que colocar o corpo em movimento é performar um tipo de conhecimento como aliado na produção de saberes que deem conta das singularidades vividas no cotidiano dos processos de trabalho em saúde.

A montagem dessa intervenção consistiu em diversos exercícios afetivos e dinâmicas corporais a serem narradas, que se intercruzaram em um processo de continuum movimento.

Para acompanhar os efeitos gerados por tais experimentações foi pedido aos participantes, após a vivência, que mandassem relatos das experiências ${ }^{3}$ por e-mail. Além disso, nos valemos de anotações em um diário de campo com inspirações cartográficas.

A sistematização do cultivo e da análise dos dados se deu em forma de narrativa. A narrativa tentou se colocar ao lado do sujeito, desta forma todos os modos expressivos dos participantes foram alocados junto com a elaboração do diário de campo. Não se distanciou para análise os textos e as falas dos sujeitos. Ao contrário elas participaram de todo o texto científico impondo outro sentido para o rigor metodológico, efetivando um método coletivo e participativo em todas as etapas.

Todos os participantes foram convidados à realização de trabalhos e vivências corporais descritas como investigação proposta, não havendo critérios de inclusão e exclusão. $\mathrm{O}$ encontro foi denominado de "clínica da metamorfose"4 e seguiram uma proposta de experiência corporal e mobilização de cargas afetivas. ${ }^{5}$

\section{Clínica da metamorfose}

E hoje, como foi? Minhas mãos estavam fazendo carinho no papel para poder aproximar e deixar aqui algo do que foi sentido. Porque é mais que as palavras expostas (LÚNULA, 2013).

Dentro de um Programa de Pós-Graduação em Saúde Coletiva as carteiras são cuidadosamente remanejadas para o corredor. Na intenção de conscientizar a mecanização dos gestos, lubrificar as articulações do corpo e para deixar o que cabe no invisível transbordar em nossa pele, foi preciso "empurrar" alguns equipamentos insti-

\footnotetext{
${ }^{3}$ Trechos dos relatos de experiências que nos foram enviados por e-mail serão apresentados a seguir, sempre em itálico, a fim de destacá-los do texto.

${ }^{4} \mathrm{~A}$ escolha do nome "clínica da metamorfose" para a intervenção proposta deveu-se à afirmação de que a prática de experimentação corporal possui efeitos clínicos transformadores, engendrando mudanças corporais-subjetivas importantes nos participantes. Deixaremos para outra oportunidade a discussão acerca das relações entre prática clínica e pesquisa porque consideramos que essa temática foge ao escopo desse artigo.

${ }^{5}$ Como uma das considerações éticas, o projeto foi encaminhado ao grupo de pesquisa Rizoma - Saúde Coletiva e Instituições do Programa de Pós-Graduação em Saúde Coletiva da UFES para anuência. Em seguida o projeto foi submetido à Plataforma Brasil e obteve sua aprovação pelo Comitê de Ética e Pesquisa (CEP) do Centro de Ciências da Saúde desta Universidade sob Certificado de Apresentação para Apreciação Ética (CAAE) número: 5762113.6.0000.5060. De acordo com o Termo de Consentimento Livre e Esclarecido (TCLE), os nomes dos sujeitos não serão revelados em nenhum momento do artigo. Com vias a esta preservação e sustentando a intenção de experimentar formas de acesso ao corpo utilizamos nomes não usuais de acidentes anatômicos para representar cada participante.
}

tuídos. Aparelhos que demarcam espaços e constrangem agitações para formar corpos/alunos. ${ }^{6}$ Não se trata apenas de ganhar espaço, mas retirar para multiplicar.

É preciso fazer o múltiplo, não acrescentando sempre uma dimensão superior, mas, ao contrário, da maneira simples, com força de sobriedade, no nível das dimensões de que se dispõe, sempre n-1 (é somente assim que o uno faz parte do múltiplo, estando sempre subtraído dele). Subtrair o único da multiplicidade a ser constituída; escrever a n-1 (DELEUZE; GUATTARI, 1995, p. 13).

Retirar as carteiras vistas como a única possibilidade de ser sala de aula para multiplicar gestos. Retirar o que enche para deixar caber a diferença. Uma sala de aula se desfigura. As carteiras dão lugar para balões, muitos balões, um tapete de balões que parecem convidar outros movimentos. O cenário também muda com novos nuances de luz e imagens.

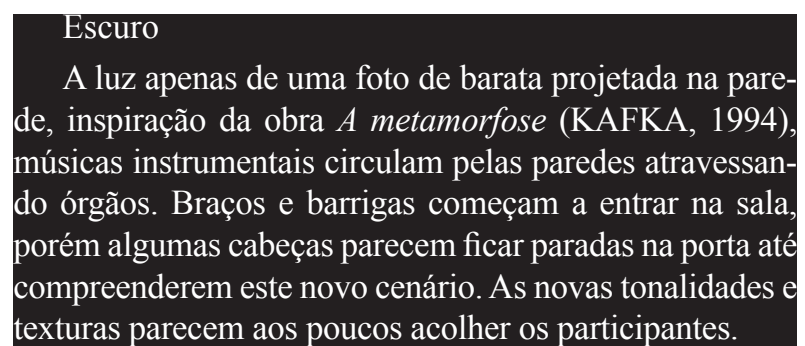

Quando as luzes se apagaram senti que já era hora de me deixar levar, o escuro da sala passava uma sensação de conforto e logo no aquecimento fiquei bem, o corpo já estava aberto para a experimentação. Os balões deixavam a sala bem interessante e pareciam se misturar com a gente, já eram parte de mim (GLABELA, 2013).

O grupo inicia o encontro pisando em bolas de tênis. Um lado por vez, os participantes transferem o peso do corpo para o pé. Pisando sobre a bola de tênis e deixando a mesma percorrer por toda sola, lentamente os ossos do pé se abrem, os músculos centralizam e relaxam, o desequilíbrio desperta concentração no movimento. Aumenta-se o espaço interno - é preciso descobrir brechas em corpos que já se conhecem travados.

Muita dificuldade em me inserir e me expressar, sou muito travado. Dito isso, passada a primeira dificuldade de realizar a tarefa, fui me permitindo sentir meu corpo e meus sentimentos que aproveitavam a "brecha" vir a tona (PTERIGÓIDEO, 2013).

Não confrontamos as relações que nos travam de forma direta, trata-se de liberar novas áreas (BEY, 2011). Nesse sentido a estratégia não está em intervir em um corpo que trava para produzir um corpo destravado, essa é uma lógica de sobreposição de poder, alternância de estados conhecidos. Apostamos no exercício de um corpo articulado, na intensificação das potências em estados de devir. ${ }^{6}$ Ao trabalhar na perspectiva do corpo como objeto e alvo do poder Foucault
(1997) disserta a respeito da disciplina como um diagrama de forças na produção
de corpos dóceis. A disciplina opera controlando a distribuição dos corpos no
tempo, espaço, gestos e composição de suas forças. A sala de aula se utilizaria de
equipamentos como as carteiras es arranjos em filas para determinar o lugar que
se ocupa e a distância que separa cada aluno no intuito de hierarquizar, individua-
lizar e organizar um trabalho simultâneo para todos. A sala de aula seria um gran-
de quadro único com corpos talhados por toda uma anatomia política do detalhe. 
Ao permitir sentir o corpo e os sentimentos, aproveitando as brechas, cultivamos uma disponibilidade aos afetos que passam a ocupar territórios ainda não registrados. Ou seja, rastreamos sensações que incidem despercebidas pelo controle da consciência. Trabalhamos com atenção ao momento presente, sentir a lógica do trabalho em ato é experimentar a duração, para além do que sou ou do que posso ser, os afetos habitam a duração enquanto multiplicidade qualitativa (BERGSON, [1988]).

Entendemos multiplicidade qualitativa como um campo de forças que, ao se agenciarem, nunca nos tocam da mesma forma - o tempo vivido não seria uma sucessão de instantes idênticos, "a duração é o que difere de si" (DELEUZE, 1999, p. 103).

Por alguns momentos me desloquei dos movimentos estereotipados, conhecidos e senti a criação brotar de dentro de mim. Foi um momento singular, único, e ao mesmo tempo que parecia durar alguns poucos minutos, acho eu! (GRÁCIL, 2013).

Portanto, operamos com a estratégia de liberar novas áreas para variarmos de nós mesmos, não brigar especificamente com um músculo tenso, mas experimentar movimentos que escapam da serialização. Movimentos estranhos que produzem consciências de pequenos acontecimentos capazes de romper com categorias e expectativas pré-estipuladas. Tais experiências constroem pontes de sentidos que nos surpreendem com novos ritmos, suavidades e formas de agir.

Tivemos muitas produções e ao mesmo tempo me sentia um pouco esgotada com tudo se resolvendo ao mesmo tempo, uma espécie de "stress" de satisfação. E enfim chegou a sexta e fui aberta para a experimentação. Senti que precisava me "libertar" (ou tentar pelo menos). Fui bem tranquila e disposta para a experimentação, e também não tentei prever o que poderia acontecer. Deixei rolar. Sai da experimentação com a sensação de estar mais leve e mais consciente do meu corpo. De onde doi e onde não doí. Do que preciso trabalhar mais e até onde posso ir ou ir além. As experimentações no geral me ajudam a trabalhar melhor com meu corpo, entender meu espaço e meus limites. Também consigo perceber o outro e todos ao meu redor porque amplia meu campo de contato (GLABELA, 2013).

Dando sequência aos exercícios fizemos contato com a terra, grounding (LOWEN, A.; LOWEN, L., 1985), enraizamento, estabelecer relação entre os movimentos voluntários, semi-voluntários e involuntários a partir da percepção de como nos sustentamos.

Alongamentos, boca sugando, língua fora, estica pescoço, enrola o corpo para um grounding invertido, fazer contato com quadril e pernas. É difícil lembrar-se das pernas quando se vive constantemente em salas de trabalho, estudos, carros, aparelhos que nos mantêm sempre sentados com a cabeça sustentada por pensamentos abstratos, longe da sala, do presente, longe até do pescoço.

Os balões espalhados pela sala são convidados a participar da respiração, atentamos para experiência do troc-ar. Com a bola de assoprar no sexo, respiramos movendo a pélvis, enquanto se libera os condicionamentos do quadril, o corpo ensaia uma possibilidade de ser um canal de passagem, deixar o ar passar sem obstruções, experimentar fluxos aéreos e todas as trocas que a respiração pode ativar.

O corpo é tão-somente um conjunto de válvulas, represas, comportas, taças ou vasos comunicantes: um nome próprio para cada um, povoamento do CsO, Metrópoles, que é preciso manejar com o chicote. O que povoa, o que passa e o que bloqueia? (DELEUZE, GUATTARI, 1996, p. 13).

A partir daí os balões se integram aos movimentos. Utilizando os mesmos realizamos massagens em todas as camadas do corpo. Iniciando com as camadas dos órgãos internos, músculos e ossos um barulho toma conta da sala. Apertando contra si os balões iniciam um ranger estridente e afloram uma imagem de objetos enferrujados. Parecia que os balões estavam abrindo dobras corroídas, portas antigas de lugares mórbidos.

\section{Silêncio e sutileza.}

A bola parece fazer carinho, aparecem rostos serenos, não trabalham mais com uma raspagem bruta. Os movimentos ganham tom de espontaneidade e leveza. Parecem intuir que o desejo habita a periferia. "O mais profundo é a pele" (DELEUZE, 2009, p. 106). Delicadamente corpos mudam em forma de suspiro e a mudança não grita, sussurra.

Outro exercício proposto é de explorar os movimentos das articulações com a bola. Descobrir movimentos com a bola de levantar e deitar. Em seguida estender esses gestos com a bola no mais alto e no mais baixo possível. Investir nas recombinações das dobras do corpo repetindo os planos (alto - baixo) diferindo nos gestos. A única repetição possível é a repetição da diferença (DELEUZE, 2006).

Movimentos de ondulação ${ }^{7}$ invadiam a sala produzindo quebras de rigidez e gestos robóticos. Trazemos um clima leve e agradável aos gestos. Além disso, os movimentos de ondulações que surgiam aparecem como formas de resistir aos movimentos retilíneos que a cidade impõe. Com seus caminhos, estradas, escadas, elevadores sempre retos e diretos. A partir do passeio que a bola fazia pelas curvas dos ombros, cotovelos e joelhos, construíram-se desenhos e contornos que desbloqueavam com leveza e alegria as formas enrijecidas pelas retas da cidade. Após brincar com as bolas nas articulações, trabalhamos com o lançamento. Jogar a bola para cima e inventar um movimento enquanto ela cai. Dançar com a gravidade agindo sutilmente na bola. Deixar que o quase sem peso disparasse novas coreografias. O que mais me tocou foi estabelecer um outro tipo de relação com o balão que até então não tinha ocorrido nem em pensamento (TRÓCLEA, 2013).

Dançar com os balões foi lindo, ver quantos movimentos novos fiz junto com o balão. E fiz sem medo de que estourassem, e não me preocupei com isso, até achei que eles nunca estourariam (GLABELA, 2013).

${ }^{7}$ A bioenergia, segundo Reich, flui em movimentos ondulatórios e sua característica dinâmica básica é a pulsação (CAPRA, 1995). Quanto mais dissolvidas as couraças musculares Reich observou que suaves movimentos ondulatórios involuntários surgiam rompendo com imobilidades musculares e tensões crônicas desenvolvidas por nossa história emocional. 
Após uma série de lançamentos e danças um momento para cair junto com a bola, ir ao solo, despencar um corpo que já se aproximou de diversas provocações nos sentidos. Ao deitar, um convite a encontrar-se com algo repugnante que o constitui. Dar forma e depois movimento a isso - cada vez mais intenso. Começam a surgir uma complexidade de caretas. Caretas que assumiam formas de estranhamento, nojo, medo e sustos em poder parecer com o que se sente. Os corpos se fecharam, travaram. Dar intensidade a essas forças era importante para fazer contato com a repugnância em nós, se retrair, se encolher para assimilar a experiência de repugnância - sentir para devir.

E neste abalo tudo se entorta e revira. Nesta noite com o grupo Rizoma a Metamorfose... Me senti o avesso e pude me metamorfosear com os outros corpos (GRÁCIL, 2013).

Depois de intensificar ao máximo uma forma repugnante, adicionamos a bola como parte da repugnância, um dispositivo para iniciar exercícios de fusão. "O problema não é mais aquele do Uno e do Múltiplo, mas o da multiplicidade de fusão, que transborda efetivamente toda oposição do uno e do múltiplo" (DELEUZE; GUATTARI, 1996 p. 15).

Vamos ao repugnante. Um sentimento que fez meu corpo travar, se fechar e quando parei pra ver eu estava totalmente contida em mim. Numa posição trancada. Nem os olhos poderiam ver, pois estava pra dentro. Intensificar, intensificar até não caber mais naquele espaço que fiz pra mim. Se mostra um movimento forte dos pés que mexe sentindo o que é repugnante, a ponto de doer. Não sei como entra em cena o balão. E viramos um, com o mesmo movimento de sensação (LÚNULA, 2013).

Após muitas torções, estouros de balão, raivas e repúdios um novo cenário se monta. A proposta é se deixar atrair por outros estímulos e movimentos presentes à nossa volta. Se encontrar e compor com outros corpos esta repugnância. Este outro corpo que não necessariamente é outra pessoa, mas os corpos disponíveis na sala - parede, chão, outras bolas, ar, luz...

Se unir aos novos encontros para que a repugnância seja povoada. Construir zonas de povoamento com os "enementos" que circulam em nossos contornos. Perceber que a produção de encontros estabelece zonas de passagem para que novos fluxos remontem novos corpos. Movimento trabalhado, trabalhado, até derreter e virar outro movimento. Ufa, agora suave (LÚNULA, 2013).

A repugnância some - a coreografia se sintoniza com toques delicados quase que assentando o ar dentro dos poros, inflando a pele com movimentos sutis. Entendemos que o desejo se faz enquanto agenciamento, um desejo é sempre coletivo, uma força conectiva que se alimenta de entorno e persiste em acontecer. Para tanto, se instigava como incluir cada vez mais elementos aos corpos e, com isso, intensificar as tensões para criar zonas de variação. Estas inclusões agitavam a sala espalhando as bolas e misturando os corpos. Neste sentido, os encontros se davam constantemente e sempre abalavam

\footnotetext{
${ }^{8}$ Neologismo proveniente de $n=$ infinito (BAREMBLITT, 2008).
}

Fractal, Rev. Psicol., v. 29 - n. 2, p. 183-190, 2017 as formas organizadas. Abandonando os automatismos inauguravam-se encontros que, em cada perturbação, geravam uma novidade.

Uma possibilidade para pensar uma produção de conhecimento que surge por encontros e perturbações mútuas conforme uma máquina autopoiética (MATURANA; VARELA, 2002). Tal máquina agencia uma cognição autopoiética (KASTRUP, 1999) um processo de incorporação das mútuas perturbações que engendravam respostas criativas.

Quais as formas pelas quais um indivíduo se pensa e se reconhece como sujeito? Através de que modalidades sai em busca de si mesmo? Que experiências realiza para dar sentido à sua existência? Estas são as questões levantadas por mim após a experiência que vivenciei junto ao grupo Rizoma. A experiência foi fantástica, pois através dela puder me redescobrir/remodelar através do contato com outro e com os baloes. (HELICOTREMA, 2013).

Nestes encontros, a alegria enquanto vontade de agir e se mexer ia se expandindo. Ganhava a sala e fragilizava as formas duras e grossas da repugnância. Alegria de celebrar um novo encontro e o desprendimento para mover-se sem medo ou restrições.

O que mais me pegou realmente foi a metamorfose do que era repugnante em mim [...] Ao me deparar com outros corpos, outras coisas e muitos balões, me desprendi do meu eu repugnante e cai no desapego de tudo!!!

Sem falar da liberdade que senti me envolvendo em andares, coreografias, afetos [...] (PALATINA, 2013).

Aprender sobre as aberturas do corpo e as modulações do aproximar ampliou um campo de consistência aos desejos que se misturavam em outras superfícies e produziam linhas de fuga - uma metamorfose.

O momento onde foi pedido para imaginar e pensar sobre o que era de mais repugnante em nós foi terrível. Era para ser assim mesmo, afinal, não é fácil lidar com o que há de mais horrivel em nós, porém ainda assim foi uma surpresa as coisas que senti, pensava: Isso não acaba! Passa logo outros comandos! Aí os próximos foram em torno de uma forma para essa repugnância, só acabou com tudo, angústia sem tamanho. Apesar disso a sequência foi salvando a situação, a angústia se dissipando e o corpo relaxando as tensões (PTERIGÓIDEO, 2013).

Uma delicia andar, me arrastar entre as bolas, ou sentir com força, ora sentir tão suave, como uma brisa. Que coisa boa. Ter sensações gostosas com as coisas, com a sala, com a luz do datashow. Um corpo aberto, com olhos em tudo. Pele que sente. Formar com o outro e tentar ser e dar o melhor naquele momento. Bom momento. Relaxante. Sentir a bola, a sala, o chão, a mão gelada do Manguito rotador. Vivo (LÚNULA, 2013).

Desta forma acredita-se construir uma política do sensível. Dramatizar a potência de um corpo enquanto produção de territórios, potências e coletivos (DELEUZE; GUATTARI, 1996). Um corpo praticado de tal maneira que ele só pode ser ocupado, povoado por intensidades. Ele não é espaço e nem está no espaço, é matéria 
de contato e composição, um corpo que responde às afetações, conhece e se alia ao sutil - guerrilha do movimento agenciando novas realidades. Corpo que se define não como algo que se tem, mas antes, como corpo que se faz (MOL; LAW, 2004) num processo contínuo de agenciar, conectar elementos díspares e heterogêneos: a alegria, o gesto, o balão, o som. Corpo que se define como conexão a fazer: quanto mais conexões, mais porções de mundo se inauguram, mais diferenciações se abrem à experiência (LATOUR, 2004). Desse modo, a formação em saúde é prática que incide também sobre cuidar de quem cuida, mobilizar o corpo de quem cuida, ampliar suas redes de ação, suas possibilidades de afetar e ser afetado pelo mundo. Fazer um corpo é um processo dinâmico, contínuo, vital para produzir uma formação em saúde, para articular cuidado e formação.

Travei um pouco quando falamos das coisas ruins, mas acho que é porque as coisas ruins "travam" mesmo a gente, ou me travam. Quando tive que intensificar fiquei inquieta, mas intensifiquei com a ajuda dos balões. E a partir dai as coisas foram melhorando porque passou a ser outra coisa e uma outra coisa mais alegre e colorida (GLABELA, 2013).

Ao final em duplas propomos cada um perguntar ao outro o que ele gostaria de receber, uma forma de cuidar atentamente do outro.

Depois durante a massagem com o outro me senti novamente muito bem, é bom cuidar do outro e da mesma forma me deixei ser cuidada. Foi uma forma de tirar o que tinha sobrado de tensão no corpo, tanto meu quanto do meu parceiro. Nos permitimos (GLABELA, 2013).

Naquela "sessão de descarrego" no final entrei mais no clima tentando descarregar todas aquelas sensações ruins, e depois o que veio foi só alivio e tranquilidade. Uma montanha russa de sensações! Acho que isso que descreve a experiência, e acho que metamorfose tem muito haver com isso, pois, não necessariamente, o processo é linear ou estável (PTERIGÓIDEO, 2013).

Repugnante em mim, só consegui pensar no meu jeito controlador de viver a vida...e assim me enrijeci mais ainda. Sempre que começo a vivenciar, a primeira coisa que sinto é como estou rígida, com os músculos doloridos e vou sentindo cada vez mais a medida que a vivencia progride. Depois à medida que vou tomando contato com meu corpo vou relaxando e começo a sentir prazer e alegria. Ontem, quando Grácil me tocou na hora troca de "do que você precisa?", ela tomou um susto quando começou a massagem nos meus ombros, tamanha tensão que havia neles (imagina se ela tivesse me tocado no começo, quando a tensão era muito maior?). Então, ao final, senti que consegui ter consciência da forma que estava, comecei a me "mexer", sair da forma, mas não completamente (ÍNIO, 2013).

O cuidado então aparece como um elemento invisível que estica as bocas em sorrisos e lubrifica os quadris em danças cada vez mais soltas. Cuidar na dimensão de estar junto e se deixar alterar pelos múltiplos encontros parece uma forma de dar consistência às conexões do desejo e sua materialidade. Aprender a existir entre tonalidades, toques e ritmos que nos invadem constantemente - cuidado como uma trilha se abrindo para novos povos.

Desfazer o organismo nunca foi matar-se, mas abrir o corpo a conexões que supõem todo um agenciamento, circuitos, conjunções, superposições e limiares, passagens e distribuições de intensidade, territórios e desterritorializações medidas à maneira de um agrimensor (DELEUZE; GUATTARI, 1996, p. 22).

Por fim, nesta intervenção, alegria e múltiplos encontros aparecem como pistas no exercício da metamorfose. Redimensionar as formas a partir das bordas. Provocar e incorporar cada toque. Um esforço para dar conta do sensível das coisas, de tudo que elas não dizem. Perseguir aquilo que escapa à expressão ordinária e se deparar com a infinita variedade de ser das coisas mais singelas.

Tal é a formação que desejamos produzir. Um espaço que investe na possibilidade de exercitar um corpo-trabalho poroso. Ou seja, corpos sensíveis e atentos aos encontros, corpos que possam considerar o diálogo por meio de suas diversas formas de comunicação, corpos que se apresentam abertos ao acolhimento, levando em conta os saberes, as crenças, as expectativas e as necessidades do encontro. Aprender sobre a experiência de um corpo em movimento e suas metamorfoses podem ser formas de se perceber fazendo saúde e refletir sobre esse processo.

\section{Conclusão}

Ao considerar a dimensão porosa do corpo, considera-se, então, o corpo enquanto uma substância capaz de afetar e ser afetada, um território de perturbações e impulsos que, em constante movimento, desenha organizações, modos de funcionamento, modos de agir, sentir e estar no mundo. Tem-se o corpo como efeito das composições e decomposições provocadas nos encontros, dando textura à cada experiência. $\mathrm{O}$ corpo tecido no emaranhado de conexões locais e situadas. O corpo que não está dado. Há que se fazê-lo, dia após dia. Mais articulações, mais porções de mundo que se abrem, mais sensível e poroso se torna o corpo. O corpo tem a potência de se contrair e expandir, provocando fechamento e abertura às trocas de experiências. $\mathrm{O}$ corpo se apresenta como um campo de batalha, com marcas de lutas históricas, e pulsa em sua instância criadora. O desafio é tornar visível caminhos que partem do pressuposto de que a vida é inseparável do corpo que adoeceu - não segue um fluxo ordenado, mas faz conexão com o que se permite passar pelos poros.

A partir do que já foi exposto, para compreender os modelos tecnológicos e assistenciais é preciso ver a atualização das tecnologias de cuidado e sua relação com os corpos, para tanto é preciso criar espaços em que um corpo se expresse enquanto campo de conexões e contágios. A utilização do mesmo como dispositivo implica em experiências de raspagens. A raspagem consiste em uma desobstrução dos corpos cheios de registros e controles, ativando campos de passagens, diferenciação e movimento: corpos sensíveis. Ou seja, a liberação das reações automáticas, movimentos estereotipados e condicionamentos orgânicos fabricados por instituições. Ao 
lado das tecnologias disciplinares sobre o corpo - busca-se habitar o lugar da desconstrução do organismo produzido por essas disciplinas (QUILICI, 2004).

Não é apenas nas grandes crises, na doença e na morte, que o corpo se instabiliza. Produzir momentos de instabilidade enquanto práticas de si permite um aguçamento da percepção. A apreensão dos movimentos microscópicos dos estados físicos pode deixar pistas por novos modos de apreensão do corpo. A experiência da raspagem e produção de um movimento de recomposição do corpo permite experimentar um estado de presença caber na própria pele sem medo dos inconscientes que nela habitam e protestam.

Através desta geografia afetiva, a figura do sujeito individualizado se dissolve, abrindo espaço para corporificar e atender demandas das coletividades. Neste trabalho de desfiguração pressente-se o ensaio de um novo corpo, permeável às forças naturais, perdido no rastro dos arrepios, vivendo a integração antes impensável entre sujeito e objeto. Um conhecimento implicado no plano concreto da experiência (PASSOS; BARROS, 2010). Uma atitude que provoca e captura tudo aquilo que não é, mas poderia ter sido.

Entende-se que o cuidado se efetiva quando cria conhecimento, não impõe formulações. Para tanto é preciso fazer escolhas por inversões metodológicas, pois qualquer critério de validação dado a priori não é capaz de construir conhecimento, no máximo se atribui valores de certo/errado, se julga. Não é preciso conhecer para julgar e reproduzir. Não é possível preparar o conhecimento e torná-lo possível (DELEUZE, 2002). Este deve ser cultivado com os jogos de corpos e suas marcas, uma escolha ética pelo conhecimento.

Tal participação permite devolver o corpo às pesquisas e a emoção ao pensamento, colabora para uma política emancipatória de cuidado, fruto de disposições que podemos cultivar em grupo.

A partir do compromisso com a participação dos sujeitos, seus relatos não se distanciam do processo, ao contrário. Para além de análises decalcadas que excluem a dinâmica dos sujeitos nas cenas experimentais, suas narrativas devem compor os relatórios por entre a construção dos procedimentos. Os relatos dos sujeitos funcionam como ferramentas que abrem passagens e encontram brechas para uma escrita em conjunto, para a elaboração conjunta de processos formativos. Retalhos costurados que pintam os afetos emergentes.

Nesse sentido, a porosidade do corpo não se apresenta como um conceito, mas um conjunto de práticas a serem cartografadas, destinadas à dissolução de organismos feita por mapas doutrináveis que se encerram em leituras e representações. Trata-se de pensar e criar práticas experimentais, com prudência e ousadia bem dosadas, que permitam desfazer automatismos e produzir um corpo poroso a outros corpos que nos circulam por contatos, fluxos e intensidades. É nessa proximidade, nesses limites territoriais que a saúde experimenta outras dimensões do real, implicando seus atores a assumir uma nova atitude diante a existência.
Um treinamento dos poros - corpo de combinações e à espreita. Criar campos imanentes, consistentes e atentos à produção de comum - dar voz a sensibilidades que circulam à flor da pele. Retomar o corpo na sua dor e no encontro com a multidão da exterioridade, condição de corpo afetado. Ampliar a capacidade de acontecer e celebrar as surpresas do cuidado. Por isso, o cuidado é a referência dos serviços de saúde e a estratégia radical para defesa da vida (MERHY; FEUERWECKER; GOMES, 2010).

Agenciar um encontro dançante entre corpo, cuidado e formação inventa uma coreografia sempre em deriva, capaz de produzir vínculos e relações acolhedoras ao som de diversas ações integrais à saúde.

Trata-se de um posicionamento de luta para que as políticas públicas se efetivem por meio de "corpos políticos": implicados com processos coletivos de construção de mundo; "corpos éticos": trazendo nas relações uma atitude de acolher a diferença; e "corpos estéticos": comprometidos a experimentações e atentos a um regime de afetos, para que nos diversos encontros do cotidiano novas coreografias possam ser geradas. Posicionamentos estes que interferem diretamente na invenção de ofertas que potencializem a atenção e formação em saúde para a população.

A bola é bola. Cansou. Virou mão que massageai, e agora já é vento com forma e cor. Bola que é palavras. Mas antes foi pele. E pode ser um monte de coisa. É só dar bola (LÚNULA, 2013).

\section{Referências}

ALMEIDA FILHO, N. A ciência da saúde. São Paulo: Hucitec, 2000.

AYRES, J. R. C. M. Cuidado e reconstrução das práticas de Saúde. Interface (Botucatu), Botucatu, v. 8, n. 14, p. 73-92, fev. 2004. Cross ${ }^{\text {Ref. }}$

BAREMBLITT, G. Dez proposições descartáveis acerca do esquizodrama. 1 fev. 2008. Disponível em: <http:// artigosgregorio.blogspot.com.br/2008/02/dez-proposiesdescartveis-acerca-do.html>. Acesso em: 25 jun. 2013.

BAREMBLITT, G. Introdução à Esquizoanálise. 3. ed. Belo Horizonte, FGB/IFG, 2010.

BERGSON, H. Ensaio sobre os dados imediatos da consciência. Lisboa: Edições 70, [1988].

BEY, H. TAZ: zona autônoma temporária. 3. ed. São Paulo: Conrad, 2011.

CAPRA, F. O ponto de mutação. 10. ed. São Paulo: Cultrix, 1995.

CARVALHO, Y. M.; CECCIM, R. B. Formação e educação em saúde: aprendizados com a Saúde Coletiva. In: CAMPOS G. W .S et al. (Org). Tratado de Saúde Coletiva. São Paulo: HUCITEC; Rio de Janeiro: FIOCRUZ, 2009. v. 2, p. 137-171.

DELEUZE, G. Bergsonismo. Rio de Janeiro: Editora 34, 1999.

DELEUZE, G. Espinosa: filosofia prática. São Paulo: Escuta, 2002.

DELEUZE, G. Diferença e repetição. 2. ed. rev. e atual. São Paulo: Graal, 2006. 
DELEUZE, G. Lógica do sentido. 5. ed. São Paulo: Perspectiva, 2009.

DELEUZE, G.; GUATTARI, F. Mil platôs: capitalismo e esquizofrenia. São Paulo: Editora 34, 1995. v. 1.

DELEUZE, G. GUATTARI, F. Mil platôs: capitalismo e esquizofrenia. São Paulo: Editora 34, 1996. v. 3.

FOUCAULT, M. Vigiar e punir: nascimento da prisão. 16. ed. Petrópolis, RJ: Vozes, 1997.

GLABELA. Experimentação de sexta [mensagem pessoal]. Mensagem recebida por lima.thiagosousa@hotmail.com em 2 maio 2013.

GRÁCIL. Fwd: METAMORFOSE - BALOANDO A ESCRITA [mensagem pessoal]. Mensagem recebida por lima. thiagosousa@hotmail.com em 15 maio 2013.

HELICOTREMA. RELATO DE EXPERIÊNCIA. [mensagem pessoal]. Mensagem recebida por lima.thiagosousa@hotmail. com em 5 ago. 2013.

ÍNIO. Reverberações do Esquizodrama [mensagem pessoal]. Mensagem recebida por lima.thiagosousa@hotmail.com em 28 abr. 2013.

KAFKA, F. A metamorfose. 15. ed. São Paulo: Brasiliense, 1994.

KASTRUP, V. A invenção de si e do mundo: uma introdução do tempo e do coletivo no estudo da cognição. Campinas: Papirus, 1999.

LATOUR, B. Jamais fomos modernos. Rio de Janeiro: Ed. 34, 1994.

LATOUR, B. How to talk about the body? The normative dimension of science studies. Body \& Society, v. 10, n. 2-3, p. 205 229,2004.Disponívelem:<http://citeseerx.ist.psu.edu/viewdoc/ download?doi=10.1.1.495.605\&rep=rep1\&type $=p d f>$. Acesso em: 22 fev. 2017. doi: 10.1177/1357034X04042943.

LIMA, T. S. F. Por uma clínica dos poros: conhecimento e práticas em saúde a partir do exercício de um corpo sensível. 2014. 160 f. Dissertação (Mestrado)-Programa de PósGraduação em Saúde Coletiva da Universidade Federal do Espírito Santo, Vitória, 2014.

LOWEN, A.; LOWEN, L. Exercicios de bioenergética: o caminho para uma saúde vibrante. São Paulo: Agora, 1985.

LÚNULA. Fwd: METAMORFOSE - BALOANDO A ESCRITA [mensagem pessoal]. Mensagem recebida por lima. thiagosousa@hotmail.com em 10 maio 2013.

MANSO, C. C. O fazer-cuidar: seguindo práticas de cuidar nas Equipes de Saúde da Família e nos Núcleos de Apoio à Saúde da Família. 2015. 221 f. Tese (Doutorado)-Programa de Pósgraduação em Psicologia da Universidade Federal Fluminense, Niterói, 2015.

MATURANA, H. R., VARELA, F. J. A árvore do conhecimento: as bases biológicas da compreensão humana. São Paulo: Palas Athena, 2002.

MERHY, E. E. Saúde: cartografia do trabalho vivo em ato. São Paulo: Hucitec, 2002.

MERHY, E. E.; FEUERWECKER, L.; GOMES, M. P. C. Da repetição à diferença: construindo sentidos com o outro no mundo do cuidado. In: FRANCO, T. B. (Org.). Semiótica, afecção \& cuidado em saúde. São Paulo: Hucitec, 2010. p. 60-75.
MOL, A.; LAW, J. Embodied action, enacted bodies: the example of hypoglicaemya. Body \& Society, v. 10, n. 2-3, p. 43-62, 2004. Disponível em: <http://journals.sagepub.com/doi/ pdf/10.1177/1357034X04042932>. Acesso em: 27 abr. 2006.

PAIM, J. S. Desafios para a saúde coletiva no século XXI. Salvador: EDUFBA, 2008.

PALATINA. Sensações [mensagem pessoal]. Mensagem recebida porlima.thiagosousa@hotmail.com em 7 maio 2013.

PASSOS, E.; BARROS, R. D. B. Por uma política da narratividade. In: PASSOS, E.; KASTRUP, V.; ESCÓSSIA, L. (Org.). Pistas do método da cartografia: pesquisa-intervenção e produção de subjetividade. Porto Alegre: Sulina, 2010. p. 150171.

PASSOS, E.; KASTRUP, V.; ESCÓSSIA, L. (Org.). Pistas do método da cartografia: pesquisa-intervenção e produção de subjetividade. Porto Alegre: Sulina, 2010.

PIRES, M. R. G. M. Politicidade do cuidado e processo de trabalho em saúde: conhecer para cuidar melhor, cuidar para confrontar, cuidar para emancipar. Ciência e Saúde Coletiva (Impresso), Rio de Janeiro, v. 10, n. 4, p. 1025-1035, 2005.

PTERIGÓIDEO. Encontro dia 26 [mensagem pessoal]. Mensagem recebida por lima.thiagosousa@hotmail.com em 27 jul. 2013.

QUILICI, C. S. Antonin Artaud: teatro e ritual. São Paulo: Annablume; Fapesp, 2004.

ROLNIK, S. Cartografia sentimental: transformações contemporâneas do desejo. Porto Alegre: UFRGS; Sulina, 2006.

TRÓCLEA. Sensações Metamorfose [mensagem pessoal]. Mensagem recebida por lima.thiagosousa@hotmail.com em 2 maio 2013.

Recebido em: 31 de março de 2017 Aceito em: 30 de junho de 2017 